
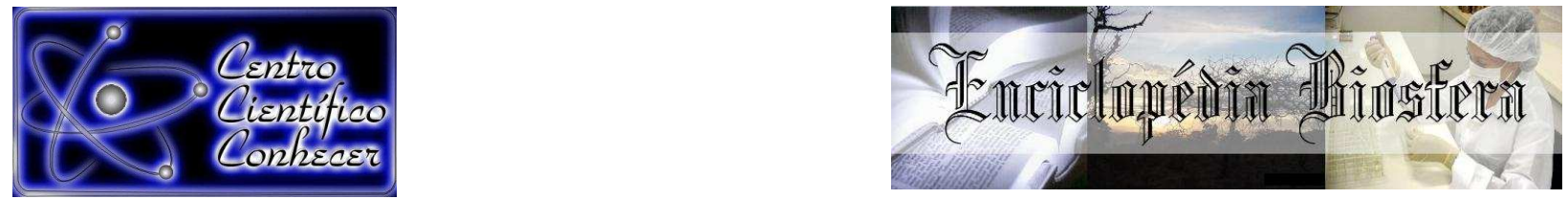

\title{
CARACTERIZAÇÃO DE UM FRAGMENTO URBANO DE MATA ATLÂNTICA EM GOIÁS
}

\author{
Angélica Ferreira Júnior ${ }^{1}$ Cristiane Iracema Monteiro Estevão ${ }^{2}$ Laura Rezende Souza ${ }^{3}$ \\ Paula Assis Lopes ${ }^{2}$ Wendy Carniello Ferreira ${ }^{4}$ \\ 1 Engenheira Florestal. Universidade Federal de Goiás - Regional Jataí. E-mail: \\ angel_engflorestal@hotmail.com \\ 2 Aluna do mestrado em agronomia. Universidade Federal de Goiás - Regional \\ Jataí.
}

3 Aluna do curso de graduação em engenharia florestal. Universidade Federal de Goiás - Regional Jataí.

4 Prof. do curso de graduação em engenharia florestal. Universidade Federal de Goiás - Regional Jataí.

Recebido em: 03/10/2016 - Aprovado em: 21/11/2016 - Publicado em: 05/12/2016 DOI: 10.18677/EnciBio 2016B 018

\begin{abstract}
RESUMO
Este estudo teve como objetivo descrever a composição florística, a estrutura fitossociológica e o efeito de borda e do fogo de um fragmento de Mata Atlântica localizado no perímetro urbano de Jataí, GO. Foram alocadas 24 parcelas de $10 \mathrm{x}$ 10 metros, sendo oito parcelas no tratamento borda, oito parcelas centro e oito parcelas próximas à margem do rio que corta o fragmento. Foram levantados todos os indivíduos com DAP $>5 \mathrm{~cm}$. As espécies foram classificadas quanto à síndrome de dispersão, ao grupo ecológico e à fitofisionomia. Calculou-se os parâmetros fitossociológicos: frequência, densidade, dominância, índice de diversidade de Shannon e o índice de equabilidade de Pielou para analisar a diversidade do fragmento. As famílias predominantes na área foram Meliaceae com 47,6\%; Piperaceae e Sapindaceae com 22,2\% cada uma; Fabaceae, com 20,6\% e Lauraceae, com 14,9\% de um total de 143 indivíduos tomados. A síndrome de dispersão predominante foi a zoocoria em $76 \%$ das espécies e o grupo ecológico predominante foi de espécies não pioneiras com $60 \%$ das espécies. $O$ índice de Shannon encontrado para área toda foi de 3,40 , considerado na média em relação às outras áreas com situação semelhante. A equabilidade de Pielou foi de 0,88 . A análise estatística quanto ao efeito de borda, mostrou diferença significativa para as variáveis Riqueza e Densidade. A partir dos resultados encontrados pode-se verificar a existência de diversidade, demonstrando a importância desse fragmento de refúgio de Mata Atlântica, dentro da área urbana da cidade de Jataí, GO.
\end{abstract}

PALAVRAS-CHAVE: efeito borda. floresta estacional semidecidual. floresta urbana. 


\title{
CHARACTERIZATION OF AN ATLANTIC FOREST URBAN FRAGMENT IN STATE OF GOIÁS, BRAZIL
}

\begin{abstract}
This study aimed to describe the floristic composition, vegetation structure and the edge effect and fire effect of a fragment of atlantic forest "Jardim Botânico Mata do Açude", located in the urban area of Jataí - GO. They were allocated 24 plots of $10 \mathrm{x}$ 10 meters, 8 plots near the edge, 8 plots near the center and 8 plots close to the river that cuts the fragment. All individuals with $\mathrm{dbh}>5 \mathrm{~cm}$ were scheduled. Species were classified as type of dispersal, the ecological group and phytophysiognomy. The phytosociological parameters were calculated: Frequency, density, dominance, Shannon diversity index and Pielou evenness index to analyze the diversity of the fragment. Families predominate in the area were $47.6 \%$ Meliaceae, Sapindaceae and Piperaceae 22.2\% each, Fabaceae $20.6 \%$ and Lauraceae to $14.9 \%$ of a total of 143 individuals taken. The predominant syndrome was zoochory dispersion with $76 \%$ of species and the ecological group predominant was non-pioneer species, with $60 \%$ of species. The Shannon index found for the whole area was 3.40 , considered in the average compared to other areas with similar situation. The Pielou evenness was 0.88. Statistical analysis on the edge effect and fire, had significant difference to variáves richness and density. From the results found you can verify the existence of great diversity, demonstrating the importance of this Atlantic Forest refuge fragment, within the urban area of the city of Jataí, GO.
\end{abstract}

KEYWORDS: Edge effect. Tropical semideciduous forest. Urban forest

\section{INTRODUÇÃO}

De acordo com o INSTITUTO BRASILEIRO DE FLORESTAS (2016), a biodiversidade da Mata Atlântica é semelhante à biodiversidade da Amazônia. Há subdivisões do bioma da Mata Atlântica em diversos ecossistemas devido a variações de latitude e altitude. Da flora, 55\% das espécies arbóreas e 40\% das nãoarbóreas são endêmicas, ou seja, só existem na Mata Atlântica. Das bromélias, $70 \%$ são endêmicas dessa formação vegetal, palmeiras, 64\%. Estima-se que 8 mil espécies vegetais sejam endêmicas da Mata Atlântica.

A área de Mata Atlântica originalmente cobria 1.047.908,08 ha, 3,08\% do estado de Goiás. Esta área é proporcionalmente pequena em relação à área de domínio do Cerrado no estado. Ao contrário de estados como Rio de Janeiro, Espírito Santo e Santa Catarina, inteiramente cobertos pela diversidade das fisionomias da Mata Atlântica, Goiás conta somente com a floresta estacional semidecidual, caracterizada pela vegetação arbórea que perde entre $20 \%$ e $50 \%$ de suas folhas no período da seca (CAMPANILI \& SCHÄFFER, 2010).

$\mathrm{O}$ atlas dos Remanescentes Florestais e Ecossistemas Associados da Mata Atlântica (período de 2000-2005), coordenado pela Fundação SOS Mata Atlântica, mostra o quanto a destruição da Mata Atlântica no estado continua evoluindo. Em 2000, Goiás possuía aproximadamente 48.400 hectares de mata, ou 3,99\% em relação à área original no estado. Em 2005, esse número havia caído para cerca de 44.300 ha ou $3,66 \%$ da área original. O desmatamento equivaleu, assim, a mais de 4.000 ha ou $8,38 \%$ entre 2000 e 2005, o que deu a Goiás o título de estado que, proporcionalmente aos remanescentes, mais desmatou no período. Segundo o mesmo Atlas (período 2005-2008), o desmatamento no estado de Goiás alcançou ENCICLOPÉDIA BIOSFERA, Centro Científico Conhecer - Goiânia, v.13 n.24; p.197 2016 
733 ha, diminuindo a área de remanescentes bem preservados para 37.649 ha (CAMPANILI \& SCHÄFFER, 2010).

As florestas urbanas são reflexos dos processos de uso e ocupação das terras, que fragmentaram e isolaram a vegetação nativa em pequenos remanescentes nos centros urbanos. A análise do processo histórico das ações de preservação das florestas urbanas, criação e gestão permite compreender, fortalecer e reconhecer a importância destas áreas (GUIRÃO \& FILHO, 2011). Nesse contexto, os parques urbanos e espaços verdes têm uma importância estratégica para a qualidade de vida da crescente sociedade cada vez mais urbanizada (PRADO JÚNIOR et al., 2012). Além disso, a utilização das florestas urbanas como área de desenvolvimento de atividades ambientais, pesquisa e preservação permanente dos ecossistemas naturais presentes e como unidade de conservação podem minimizar os impactos ambientais sofridos (TANUS et al., 2012).

No Sudoeste Goiano, as atividades agropecuárias reduziram de forma drástica todas as fitofisionomias nativas, incluindo as de floresta estacional. Estas áreas florestais estão cada vez menores e há uma necessidade muito grande de mantê-las, além de praticamente não existirem estudos sobre esta fitofisonomia na macroregião Sul de Goiás (FERREIRA \& CONSOLARO, 2013; MILHOMEM et al., 2013). Segundo VENTUROLI et al. (2011), os fragmentos de mata atlântica em Goiás são ambientes altamente ameaçados de extinção e que estudos nestes ambientes são fundamentais para identificar o estágio atual de regeneração da floresta e nortear ações de recuperação e manejo florestal. Dentro deste contexto, este trabalho teve como objetivo caracterizar a vegetação arbustivo-arbórea de um fragmento de floresta estacional semidecidual urbano por meio da descrição da composição florística e da estrutura fitossociológica e do efeito borda sobre 0 mesmo.

\section{MATERIAL E MÉTODOS \\ Descrição da área de estudo}

O trabalho foi desenvolvido no "Jardim Botânico Mata do Açude", localizado no perímetro urbano do município de Jataí, que integra a porção Sudoeste do Estado de Goiás. Trata-se de um fragmento de Mata Atlântica fora dos limites formais do bioma, estando dentro do bioma Cerrado e a área corresponde a 38,37 hectares. A vegetação é do tipo Floresta Estacional Semidecidual.

O clima da região apresenta características de área tropical, com maior pluviosidade no verão que no inverno. Segundo Köppen e Geiger o clima é classificado como AW. A temperatura média é de $23.3^{\circ} \mathrm{C}$. A média anual de pluviosidade é de $1541 \mathrm{~mm}$ (CLIMA, 2016).

De acordo com VIDA (2015), a rede hidrográfica do município de Jataí pertence à bacia do Paraná, constituída de afluentes da margem direita do Paraíba, destacando o Rio Claro e seus afluentes, Rio Doce e Ariranha. A cidade apresenta em sua seção superior segmentos bem protegidos por matas de galerias e ciliar preservada nas áreas íngremes, ocupação de pecuária nas áreas menos íngremes e ocupação agrícola intensa na parte superior da área de drenagem próxima às nascentes. A microbacia do Córrego do Açude, conhecida como Mata do Açude, drena uma área de $6 \mathrm{~km}^{2}$ e possui uma extensão de $4,6 \mathrm{~km}$.

Com território localizado no Planalto Meridional, dominado por sedimentos antigos e faixas de derrames basálticos, o relevo apresenta-se plano suavemente ENCICLOPÉDIA BIOSFERA, Centro Científico Conhecer - Goiânia, v.13 n.24; p.198 2016 
ondulado, destacando certas elevações como Serra do Cafezal, Serra do Rio Verde e Serra do Caiapó e com a presença de formas tabulares em superfícies dissecadas a leste e nordeste. As altitudes do município de Jataí variam de 700 à 1100 metros. $\mathrm{Na}$ área de abrangência da Mata do Açude o ponto mais alto é aproximadamente 758 metros de altitude. O solo na área de estudo é o Latossolo (VIDA, 2015).

\section{Sistema de amostragem e coleta de dados}

Para o levantamento florístico e fitossociológico da vegetação foram alocadas de forma sistemática 24 parcelas de $10 \times 10 \mathrm{~m}$, sendo oito nas bordas do fragmento, oito no centro do fragmento e oito na margem do córrego do Açude (Figura 1). Foram incluídas no estrato arbóreo apenas indivíduos com DAP (diâmetro a 1,3 m de altura do solo) maior ou igual a $5 \mathrm{~cm}$.

Cada indivíduo arbóreo foi sinalizado com uma plaqueta de alumínio contendo o número da parcela e o número do indivíduo, tendo a altura, circunferência e o nome científico ou popular do indivíduo tomado. Quando possível, a identificação das espécies foi realizada no local. Os indivíduos que não foram identificados em campo foram herborizados para posterior identificação no Herbário Jataiense (UFG/Regional Jataí), seguindo a circunscrição de famílias proposta por APG III (2009).

As espécies foram classificadas quanto às síndromes de dispersão com a divisão em três grupos básicos: anemocoria (dispersão pelo vento), zoocoria (dispersão por animais) e autocoria (dispersão pela gravidade ou deiscência explosiva) (VAN DER PIJL,1969 citado por VENZKE al., 2014). Foram classificadas também segundo o grupo ecológico, adotando-se a metodologia descrita por SWAINE \& WHITMORE (1988), nas seguintes categorias: pioneiras e não pioneiras (clímax exigente de luz e clímax tolerante à sombra).

\section{Determinação dos parâmetros fitossociológicos}

Os parâmetros fitossociológicos estimados foram: riqueza de espécies; densidade (DA e DR), frequência (FA e FR) e dominância (DoA e DoR) de valores absolutos e relativos; valor de importância (VI); índice de diversidade de Shannon (H') e índice de equabilidade de Pielou (J') (FELFILI et al., 2011).

\section{Caracterização do efeito borda sobre o fragmento}

Para este estudo, considerou-se a hipótese de que existe um gradiente decrescente de degradação do fragmento da borda limítrofe com a matriz urbana até a margem do córrego do Açude, causado por incêndios e efeito borda. Para verificação desta hipótese, foi utilizado teste de médias, para três tratamentos e oito repetições (Figura 1). 

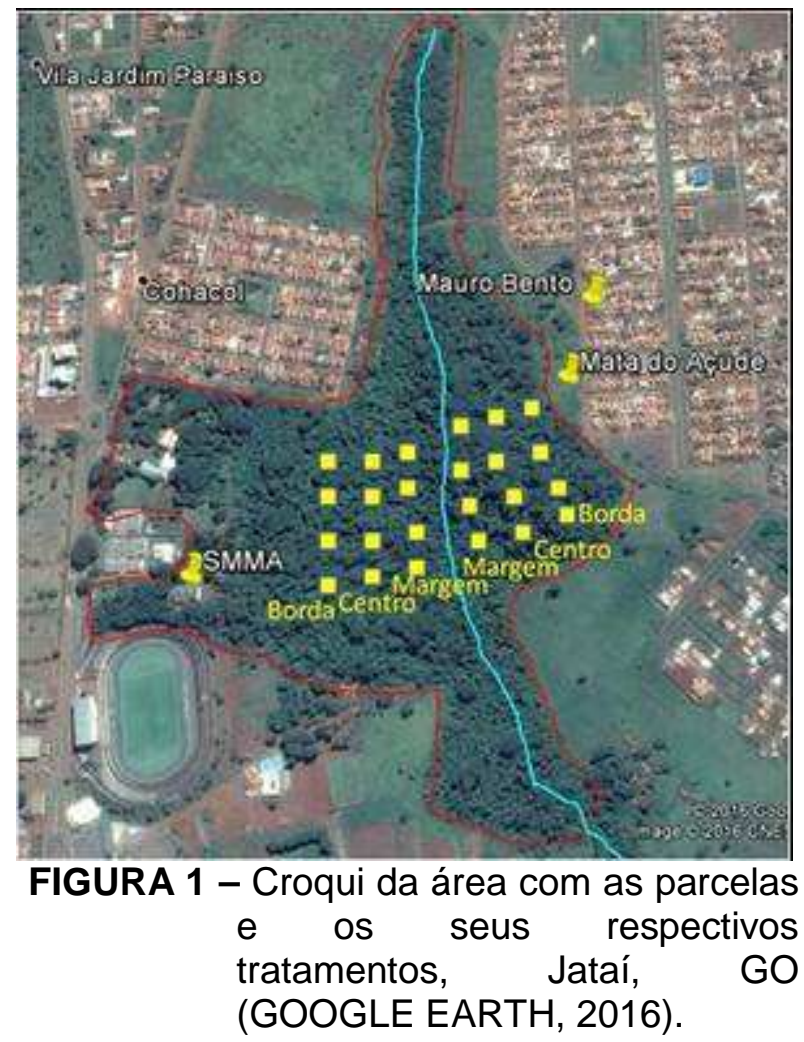

O Tratamento 1 foi denominado Borda, o Tratamento 2 Centro e o Tratamento 3 Margem. As variáveis avaliadas foram densidade absoluta, área basal, altura média e riqueza de espécies por parcela. Para comparação das médias dos tratamentos, foi utilizado o teste Tukey a $0,05 \%$ de probabilidade. As análises estatísticas foram realizadas com o programa computacional Sisvar (FERREIRA, 2014).

\section{RESULTADOS E DISCUSSÃO}

\section{Composição florística}

O levantamento florístico realizado no fragmento de Mata Atlântica gerou resultados referentes à riqueza de famílias e espécies de acordo com o critério de inserção de indivíduos no estudo (DAP $\geq 5 \mathrm{~cm}$ ). No Quadro 1 estão apresentadas as famílias e espécies, juntamente com a síndrome de dispersão, grupo ecológico e fitofisionomia.

QUADRO 1. Famílias e espécies encontradas no levantamento florístico do fragmento de Mata Atlântica com respectivas síndromes de dispersão, grupo ecológico e fitofisionomia. ANEMO: Anemocoria; AUTO: Autocoria; ZOO: Zoocoria; P: Pioneira; NP: Não Pioneira; C: Cerrado; ME: Mata Estacional; MG: Mata de Galeria. * Espécie exótica.

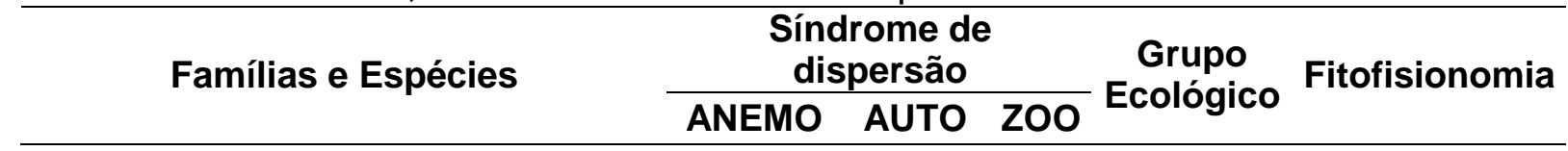

Annonaceae

Unonopsis lindimanii R.E.Fr

$X \quad P$

M.E

ENCICLOPÉDIA BIOSFERA, Centro Científico Conhecer - Goiânia, v.13 n.24; p.200 2016 


\section{Araliaceae}

Dendropanax cuneatum Decne \& Planch.

X N.P M.E

Bignoniaceae

Tabebuia roseo-alba (Ridl.) Sand

Boraginaceae

Cordia sp.

Burseraceae

Protium heptaphyllum (Aubl.)

March.

Cannabaceae

Trema micrantha (L.)Blume.

\section{Caricaceae}

Carica papaya L. *

Chrisobalanaceae

Hirtella gracilipes (Hook.f.) Prance

\section{Combretaceae}

Terminalia brasiliensis C. ex A.St.Hil. Eichler

N.P M.E

$X$

M.E

X N.P

M.G

$\begin{array}{lll}X & P\end{array}$

$x$

N.P

M.E

$X$

M.G

\section{Euphorbiaceae}

Sapium haematospermum M.Arg Alchornea triplinervia (Spreng.) M.

Arg

Fabaceae

Ormosia sp.

Bauhinia sp

Hymenaea courbaril L.

$X$

C

Senegalia polyphylla DC.

\section{Lauraceae}

Nectandra cissiflora N.

Nectandra lanceolata N.

\section{Lecythidaceae}

Cariniana estrellensis (Raddi)

Kuntze.

Melastomataceae

Miconia sp.

\section{Meliaceae}

Guarea guidonia (L.) Sleumer

Guarea kunthiana Adr. Juss.

\section{Moraceae}

Ficus benjamina L.*

\begin{tabular}{|c|c|c|c|c|}
\hline & & $X$ & $P$ & C \\
\hline & & $X$ & N.P & M.S \\
\hline & $X$ & & N.P & M.E \\
\hline$X$ & & & $\mathrm{P}$ & M.E \\
\hline & & $X$ & N.P & M.E \\
\hline & $x$ & & $P$ & M.E \\
\hline & & $X$ & N.P & M.E \\
\hline & & $x$ & N.P & M.E \\
\hline$X$ & & & N.P & M.E \\
\hline & & $X$ & N.P & M.G \\
\hline & $X$ & & N.P & M.G \\
\hline & & $x$ & N.P & M.E \\
\hline & & $X$ & N.P & M.E \\
\hline & & $X$ & N.P & M.E \\
\hline
\end{tabular}

Ficus sp. 
Myrsine umbellata Mart.

Myrtaceae

Myrtacea 1

Myrtacea 2

$x$

$x$

Psidium sartorianum (O. Berg) Nied

$\mathrm{X}$

N.P

M.E

Piperaceae

Piper sp. 1

Piper sp. 2

Piper sp. 3

$\begin{array}{lll}X & \text { N.P } & \text { M.E } \\ X & \text { N.P } & \text { M.E } \\ X & \text { N.P } & \text { M.E }\end{array}$

\section{Polygonaceae}

Coccolaba mollis Casar.

\section{Rhamnaceae}

Rhamnidium elaeocarpus Reiss.

\section{Rutaceae}

Zanthoxylum rhoifolium Lam.

$x$

$X$

$\mathrm{P}$

M.E

Sapindaceae

Cupania vernalis Cambess.

Allophylus edulis (St. Hil.) Radlk

Matayba guianensis Aubl.

$X$

N.P

M.E

Dilodendron bipinnatum Radlk.

\section{Sapotaceae}

Pouteria torta (Mart.) Radlk.

\section{Simaroubaceae}

Picramnia sp.

\section{Sterculiaceae}

Guazuma ulmifolia Lam.

\section{Urticaceae}

Cecropia pachystachya Tréc.

Urera sp.

Boehmeria sp.

$X$

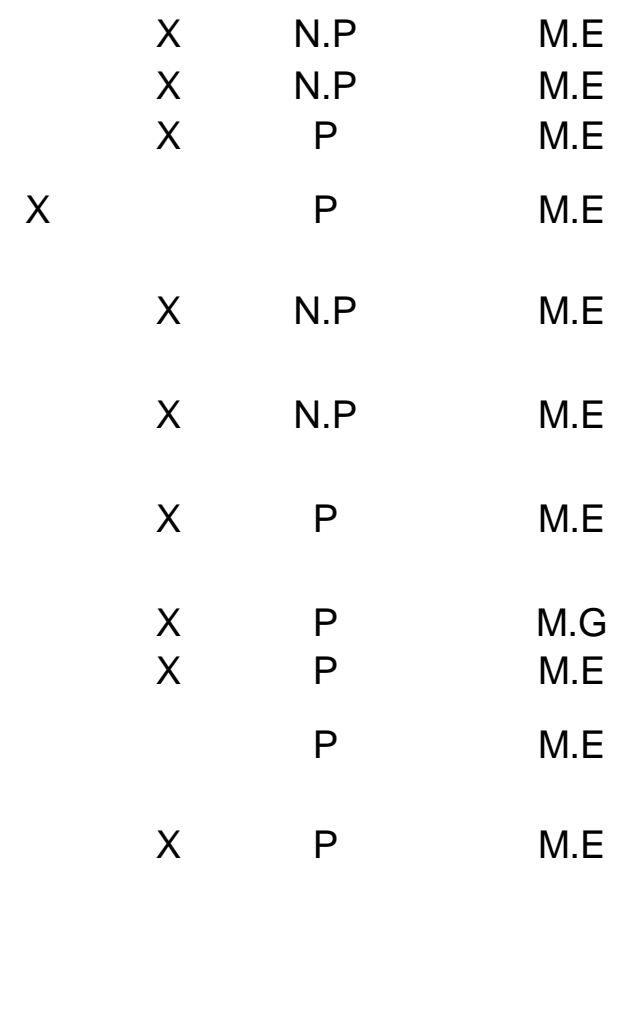

As famílias que tiveram um maior número de indivíduos na área foram: Meliaceae com 30, Piperaceae e Sapindaceae com 14 cada uma, Fabaceae com 13 e Lauraceae com nove de um total de 143 indivíduos tomados. Trata-se de algo esperado, já que as espécies da família Fabaceae estão sempre presentes em qualquer bioma brasileiro, Sapindaceae é uma família de ocorrência em 
ecossistemas florestais e ecossistemas associados à Mata Atlântica. A família Piperaceae ocorre em toda região tropical, frequentemente em locais sombreados como é o caso do fragmento estudado. A família Meliaceae que foi a que apresentou - maior número de indivíduos e de acordo com o CONAMA (1994), a família Meliaceae é considerada indicativa da passagem de floresta pioneira para um estádio sucessional mais maduro.

Outros levantamento florísticos em fragmentos de Mata atlântica (floresta estacional semidecidual) urbanos apresentaram uma grande proporção de espécies exóticas. MOREIRA \& CARVALHO (2013), em Juiz de Fora (MG), encontraram 48 espécies arbóreas, pertencentes a 24 famílias botânicas. Contudo, oito foram espécies exóticas, incluindo a primeira e a quinta com maior número de indivíduos (Pinus elliottii e Syzygium jambos, respectivamente). CIELO FILHO \& SANTIN (2002), em Campinas (SP), encontraram 105 espécies, distribuídas em 43 famílias e 67 gêneros. Oitenta espécies eram nativas e 25 exóticas, ou seja, $23,81 \%$ do total. TROIAN et al. (2011) encontraram 54 espécies pertencentes a 25 famílias em Porto Alegra (RS). Duas destas foram espécies exóticas (Juglans regia e Ligustrum sp). Em Jataí, foram encontradas apenas duas espécies exóticas (Carica papaya e Ficus benjamina), com um indivíduo cada. Este fato indica que o fragmento resiste bem à entrada e espécies exóticas que causam muitos problemas em outros fragmentos urbanos no Brasil devido à invasão biológica.

Dentro das espécies analisadas, foi possível observar quais as síndromes de dispersão predominantes. Dentre estas destacam-se zoocoria, com $76 \%$ das espécies (34 espécies), a anemocoria com 13\% (seis espécies), autocoria 11\% (cinco espécies), de um total de 45 espécies identificadas. FERREIRA \& CONSOLARO (2013), também trabalhando em um fragmento urbano de floresta estacional semidecidual em Catalão, GO, encontraram $88 \%$ de espécies zoocóricas e $12 \%$ de espécies anemocóricas no sub-bosque. Isto corrobora que a zoocoria é a síndrome de dispersão mais comum em espécies arbustivo-arbóreas de florestas tropicais ombrófilas e semidecíduas (ANGEL-DE-OLIVEIRA, 1998).

Segundo CARMO \& MORELLATO (2001), em florestas semidecíduas, a proporção de espécies zoocóricas é próxima de $60 \%$, em matas ciliares é próxima de $75 \%$ e em florestas ombrófilas é próxima de $90 \%$. É interessante notar que, apesar da mata ciliar constituir apenas uma parte do fragmento, a área estudada apresentou uma proporção de espécies zoocóricas próxima do que é originalmente encontrado em matas ciliares. Isso mostra a importância da fauna nesse fragmento estudado para a dispersão das espécies arbóreas, mesmo estando localizado dento de uma matriz urbana.

O grupo ecológico predominante foi o de não pioneiras com $60 \%$ das espécies, e as espécies pioneiras somam $40 \%$. O que mostra que o fragmento está relativamente conservado, e a porcentagem de pioneiras pode ser explicada pelas clareiras que ocorrem no local, e as trilhas dentro do mesmo. MOREIRA \& CARVALHO (2013), em Juiz de Fora (MG), num fragmento urbano de floresta estacional semidecidual, descreveram o inverso, $40 \%$ de não pioneiras e $60 \%$ de pioneiras. A diferença entre as duas áreas é que a de Juiz de Fora sofreu no passado intensa exploração madeireira e incêndios frequentes. Já a área de Jataí, apesar de apresentar incêndios com certa frequência, não tem registro de exploração intensa, como podem atestar vários indivíduos de Hymenaea courbaril encontrados no local com DAP maior que um metro. 


\section{Fitossociologia}

Na Tabela 1, observa-se que as duas espécies com os valores de importância que se destacam das demais são Guarea guidonia (Meliaceae) com 45,8 e Hymenaea courbaril (Fabaceae) com 44,9. Segundo CARVALHO (2003) e CARVALHO et al. (2007), estas duas espécies são características da Floresta Estacional Semidecidual e da Floresta Ombrófila, além de pertencerem ao grupo ecológico de secundárias tardias ou clímax. Este fato indica que o fragmento está em um estágio mais avançado da sucessão e que realmente pode ser enquadrado como um remanescente de Mata Atlântica que no passado fez parte da paisagem do sul e sudoeste goiano.

TABELA 1. Espécies encontradas no levantamento florístico do fragmento de Mata Atlântica com os resultados da análise da estrutura horizontal. ni: Número de indivíduos por espécie; ui: Número de parcelas que a espécie ocorre; G m2: Área basal em m²; DA: Densidade absoluta; DR: Densidade relativa; DoA: Dominância absoluta; DoR: Dominância relativa; FA: Frequência absoluta; FR: Frequência relativa; VI: Valor de importância.

\begin{tabular}{|c|c|c|c|c|c|c|c|c|c|c|}
\hline ESPÉCIE & ni & ui & G m2 & DA & DR & DoA & DoR & FA & FR & VI \\
\hline Guarea guidonia & 21 & 16 & 1,0674 & 87,500 & 14,685 & 4,447 & 18,130 & 66,667 & 13,008 & 45,824 \\
\hline Hymenaea courbaril & 8 & 6 & 2,0142 & 33,333 & 5,594 & 8,392 & 34,213 & 25,000 & 4,878 & 44,686 \\
\hline Guarea kunthiana & 9 & 5 & 0,5808 & 37,500 & 6,294 & 2,420 & 9,865 & 20,833 & 4,065 & 20,224 \\
\hline Allophylus edulis & 10 & 9 & 0,1436 & 41,667 & 6,993 & 0,598 & 2,439 & 37,500 & 7,317 & 16,749 \\
\hline Piper sp. 1 & 10 & 9 & 0,0249 & 41,667 & 6,993 & 0,104 & 0,423 & 37,500 & 7,317 & 14,733 \\
\hline Nectandra lanceolata & 7 & 5 & 0,1547 & 29,167 & 4,895 & 0,645 & 2,628 & 20,833 & 4,065 & 11,588 \\
\hline Rhamnidium elaeocarpus & 5 & 5 & 0,0736 & 20,833 & 3,497 & 0,307 & 1,250 & 20,833 & 4,065 & 8,811 \\
\hline Pouteria torta & 2 & 2 & 0,3067 & 8,333 & 1,399 & 1,278 & 5,209 & 8,333 & 1,626 & 8,234 \\
\hline $\begin{array}{l}\text { Sapium } \\
\text { haematospermum }\end{array}$ & 4 & 4 & 0,0941 & 16,667 & 2,797 & 0,392 & 1,599 & 16,667 & 3,252 & 7,648 \\
\hline Psidium sartorianum & 3 & 3 & 0,1542 & 12,500 & 2,098 & 0,643 & 2,620 & 12,500 & 2,439 & 7,157 \\
\hline Guazuma ulmifolia & 5 & 3 & 0,0688 & 20,833 & 3,497 & 0,287 & 1,169 & 12,500 & 2,439 & 7,105 \\
\hline Ficus sp. & 1 & 1 & 0,3151 & 4,167 & 0,699 & 1,313 & 5,353 & 4,167 & 0,813 & 6,865 \\
\hline Cecropia pachystachya & 4 & 4 & 0,0187 & 16,667 & 2,797 & 0,078 & 0,317 & 16,667 & 3,252 & 6,366 \\
\hline Urera sp. & 4 & 4 & 0,0142 & 16,667 & 2,797 & 0,059 & 0,241 & 16,667 & 3,252 & 6,291 \\
\hline Terminalia brasiliensis & 3 & 3 & 0,0642 & 12,500 & 2,098 & 0,267 & 1,090 & 12,500 & 2,439 & 5,627 \\
\hline Trema micrantha & 4 & 3 & 0,0100 & 16,667 & 2,797 & 0,042 & 0,171 & 12,500 & 2,439 & 5,407 \\
\hline Nectandra cissiflora & 2 & 2 & 0,1284 & 8,333 & 1,399 & 0,535 & 2,181 & 8,333 & 1,626 & 5,206 \\
\hline Unonopsis lindimanii & 3 & 3 & 0,0351 & 12,500 & 2,098 & 0,146 & 0,597 & 12,500 & 2,439 & 5,134 \\
\hline Protium heptaphyllum & 2 & 2 & 0,0411 & 8,333 & 1,399 & 0,171 & 0,698 & 8,333 & 1,626 & 3,723 \\
\hline Senegalia polyphylla & 2 & 2 & 0,0306 & 8,333 & 1,399 & 0,127 & 0,520 & 8,333 & 1,626 & 3,544 \\
\hline Bauhinia sp & 2 & 2 & 0,0214 & 8,333 & 1,399 & 0,089 & 0,364 & 8,333 & 1,626 & 3,388 \\
\hline Myrtacea 2 & 2 & 2 & 0,0140 & 8,333 & 1,399 & 0,058 & 0,238 & 8,333 & 1,626 & 3,263 \\
\hline Aegiphila sp. & 2 & 2 & 0,0118 & 8,333 & 1,399 & 0,049 & 0,201 & 8,333 & 1,626 & 3,226 \\
\hline Piper sp. 3 & 2 & 2 & 0,0061 & 8,333 & 1,399 & 0,025 & 0,104 & 8,333 & 1,626 & 3,128 \\
\hline Cupania vernalis & 2 & 1 & 0,0535 & 8,333 & 1,399 & 0,223 & 0,909 & 4,167 & 0,813 & 3,121 \\
\hline Piper sp. 2 & 2 & 2 & 0,0056 & 8,333 & 1,399 & 0,023 & 0,095 & 8,333 & 1,626 & 3,120 \\
\hline
\end{tabular}




\begin{tabular}{lcccccccccc} 
Carica papaya & 2 & 1 & 0,0290 & 8,333 & 1,399 & 0,121 & 0,493 & 4,167 & 0,813 & 2,705 \\
Dendropanax cuneatum & 1 & 1 & 0,0561 & 4,167 & 0,699 & 0,234 & 0,954 & 4,167 & 0,813 & 2,466 \\
Miconia sp. & 1 & 1 & 0,0390 & 4,167 & 0,699 & 0,162 & 0,662 & 4,167 & 0,813 & 2,175 \\
Zanthoxylum rhoifolium & 1 & 1 & 0,0379 & 4,167 & 0,699 & 0,158 & 0,644 & 4,167 & 0,813 & 2,156 \\
Myrsine umbellata & 1 & 1 & 0,0347 & 4,167 & 0,699 & 0,144 & 0,589 & 4,167 & 0,813 & 2,101 \\
Matayba guianensis & 1 & 1 & 0,0336 & 4,167 & 0,699 & 0,140 & 0,571 & 4,167 & 0,813 & 2,083 \\
Picramnia sp. & 1 & 1 & 0,0316 & 4,167 & 0,699 & 0,132 & 0,536 & 4,167 & 0,813 & 2,049 \\
Hirtella gracilipes & 1 & 1 & 0,0286 & 4,167 & 0,699 & 0,119 & 0,487 & 4,167 & 0,813 & 1,999 \\
Anonacea & 1 & 1 & 0,0224 & 4,167 & 0,699 & 0,093 & 0,380 & 4,167 & 0,813 & 1,892 \\
Boehmeria sp. & 1 & 1 & 0,0199 & 4,167 & 0,699 & 0,083 & 0,338 & 4,167 & 0,813 & 1,850 \\
Não identificada 1 & 1 & 1 & 0,0191 & 4,167 & 0,699 & 0,080 & 0,325 & 4,167 & 0,813 & 1,837 \\
Ficus benjamina & 1 & 1 & 0,0147 & 4,167 & 0,699 & 0,061 & 0,250 & 4,167 & 0,813 & 1,762 \\
Cariniana estrellensis & 1 & 1 & 0,0121 & 4,167 & 0,699 & 0,050 & 0,206 & 4,167 & 0,813 & 1,718 \\
Coccolaba mollis & 1 & 1 & 0,0115 & 4,167 & 0,699 & 0,048 & 0,195 & 4,167 & 0,813 & 1,707 \\
Myrtacea 1 & 1 & 1 & 0,0106 & 4,167 & 0,699 & 0,044 & 0,180 & 4,167 & 0,813 & 1,692 \\
Não identificada 2 & 1 & 1 & 0,0092 & 4,167 & 0,699 & 0,038 & 0,156 & 4,167 & 0,813 & 1,669 \\
Ormosia sp. & 1 & 1 & 0,0087 & 4,167 & 0,699 & 0,036 & 0,147 & 4,167 & 0,813 & 1,660 \\
Alchornea triplinervia & 1 & 1 & 0,0042 & 4,167 & 0,699 & 0,018 & 0,072 & 4,167 & 0,813 & 1,584 \\
Cordia sp. & 1 & 1 & 0,0042 & 4,167 & 0,699 & 0,018 & 0,072 & 4,167 & 0,813 & 1,584 \\
Dilodendron bipinnatum & 1 & 1 & 0,0042 & 4,167 & 0,699 & 0,018 & 0,072 & 4,167 & 0,813 & 1,584 \\
Tabebuia roseo-alba & 1 & 1 & 0,0029 & 4,167 & 0,699 & 0,012 & 0,049 & 4,167 & 0,813 & 1,561 \\
\hline TOTAL & $\mathbf{1 4 3}$ & & $\mathbf{5 , 8 8 7 2}$ & $\mathbf{5 9 5 , 8 3 3}$ & $\mathbf{1 0 0 , 0 0 0}$ & $\mathbf{2 4 , 5 2 9 8 5}$ & $\mathbf{1 0 0}$ & $\mathbf{5 1 2 , 5 0 0}$ & $\mathbf{1 0 0}$ & $\mathbf{3 0 0 , 0 0 0}$ \\
\hline & & & & & & & & & & \\
\hline
\end{tabular}

Verificou-se que as parcelas localizadas no centro do lado da Secretaria Municipal do Meio Ambiente (SMMA - Figura 1) possuem indivíduos que apresentam uma maior área basal, tendo $54 \%$ de toda a área basal deste lado. Contudo, a densidade de indivíduos arbóreos está mais concentrada nas parcelas da margem (Figura 1), o que demonstra que esses indivíduos não possuem um DAP (diâmetro a altura do peito $-1,30 \mathrm{~m}$ ) alto, e que os indivíduos localizados nas parcelas do centro estão com um crescimento em diâmetro maior, consequentemente explicando a maior porcentagem da área basal. Com relação às parcelas localizadas próximas ao Conjunto residencial Mauro Bento (Mauro Bento Figura 1), ressalta-se que a maior área basal está nas parcelas da margem. Já no que se refere à densidade de indivíduos arbóreos por parcela, temos uma maior concentração nas parcelas do centro (Figura 1). Entretanto, as parcelas do centro possuem um DAP menor, e consequentemente, uma área basal menor.

Com relação à altura média dos indivíduos arbóreos no lado da SMMA, foram observadas a maiores médias de altura nas parcelas do centro (Figura 1). Esta constatação se relaciona com o DAP médio apresentado pelos indivíduos arbóreos das parcelas do centro, onde indivíduos arbóreos mais altos possuem um maior DAP. Já ao lado do Conjunto Residencial Mauro Bento, as maiores alturas estão nas parcelas da borda (Figura 1), onde também tem-se uma menor porcentagem de pioneiras. Isto poderia ser explicado, ao se pensar que indivíduos que pertencem ao grupo ecológico clímax, ou secundárias, mantêm-se por mais tempo na área e, portanto, continuariam a crescer em altura e diâmetro. 
A partir dos dados fitossociológicos e da análise florística, pode-se realizar o cálculo do índice de Shannon. Os dados estão demonstrados na Tabela 2 com os resultados para o índice de Shannon e de Pielou encontrados na Borda, Centro e Margem das áreas da Secretaria Municipal do Meio Ambiente, e do conjunto residencial Mauro Bento, e os índices também foram calculados no geral para a área toda. O maior índice de diversidade foi encontrado para a área toda, com 3,40, sendo seguido pelo índice encontrado na Margem da Secretaria Municipal do Meio Ambiente, com 2,84, e pelo índice encontrado na margem do Mauro Bento, de 2,68.

TABELA 2 - Índices de diversidade e equabilidade encontrados em cada estrato e na área toda, sendo eles divididos na área da SMMA: Secretaria do Meio Ambiente, e M.B.: Mauro Bento. H': Índice de Shannon; H' máximo: Índice de Shannon ideal para a área; J': Índice de Pielou

\begin{tabular}{lccc}
\hline Estratolíndices & H' $^{\prime}$ & H' máx $^{\prime}$ & $\mathbf{J}^{\prime}$ \\
\hline $\begin{array}{l}\text { SMMMA } \\
\text { Cendr }\end{array}$ & 2,59 & 2,64 & \\
Margem & 2,60 & 2,77 & 0,98 \\
$\quad$ M.B. & 2,84 & 3,00 & 0,94 \\
Borda & & & 0,95 \\
Centro & 1,87 & 2,2 & \\
Margem & 2,60 & 2,71 & 0,85 \\
Geral & 2,68 & 2,89 & 0,96 \\
\hline
\end{tabular}

Analisando a Tabela 3, nota-se que o Índice de Shannon encontrado para o presente estudo está abaixo dos encontrados no Triângulo Mineiro, e acima do encontrado no norte do estado de São Paulo. Entretanto, estas florestas não estão localizadas em área urbana. Não há trabalhos realizados no sul de Goiás com a mesma temática, impossibilitando assim a comparação. Existem estudos em fitofisionomias de floresta estacional no nordeste de Goiás, realizados pela UnB. Contudo, estes não foram usados para comparação, pois, tratam-se de áreas localizadas nas bacias dos Rios Tocantins e São Francisco, e não do Rio Paraná, como o caso do presente estudo.

A densidade e a área basal do presente estudo estão abaixo das encontradas para outros estudos semelhantes. Estes valores podem indicar que pelo fato de a mata do açude estar localizada em área urbana, esta sofra mais distúrbios, o que reflete nos menores valores do índice de Shannon, área basal e densidade. Todos os estudos utilizados na comparação são de Floresta Estacional Semidecidual.

TABELA 3 - Comparação entre o índice de Shannon, área basal $\left(\mathrm{m}^{2} / \mathrm{ha}\right)$ e densidade (plantas/ha), encontrado neste levantamento e outros estudos em floresta estacional semidecidual em regiões próximas ao Sudoeste Goiano.

\begin{tabular}{ccccc}
\hline Local & H' & G/ha & D/ha & Autor \\
\hline Presente estudo & 3,40 & 24,5 & 600 & \\
Faz. São Pedro-Itaú, Uberlândia, MG & 3,87 & 27 & 1144 & SÁ et al. (2012) \\
Faz. São José, Uberlândia, MG & 3,53 & 34,7 & 1063 & PRADO JÚNIOR et al. \\
& & & & (2011) \\
Pindorama, SP & 3,38 & & & ABDO et al. (2015)
\end{tabular}

ENCICLOPÉDIA BIOSFERA, Centro Científico Conhecer - Goiânia, v.13 n.24; p.206 2016 


\section{Caracterização do efeito borda sobre o fragmento}

Nos quatros testes estatísticos realizados para as variáveis: densidade, área basal, riqueza e altura, foram encontradas diferenças significativas somente nas variáveis densidade e riqueza.

Verifica-se uma diferença significativa no que se refere à densidade de indivíduos arbóreos nos tratamentos da borda, centro e margem (Tabela 4). A densidade no tratamento borda é inferior à densidade dos tratamentos centro e margem. Pode-se notar um gradiente, onde a densidade tende a crescer da borda para a margem, pois mesmo a diferença do tratamento do centro não diferindo estatisticamente do tratamento margem, verificou-se que a densidade da margem é superior a densidade do centro.

Isso está relacionado com o efeito de borda, onde tem-se maior quantidade de indivíduos com menores diâmetros, e menor quantidade de indivíduos arbóreos com diâmetros acima de $5 \mathrm{~cm}$, explicando assim a menor densidade. Não deixando de levar em consideração o efeito do fogo, visto que o fragmento sofre com queimadas periódicas, e isso altera a estrutura da floresta, causando mortalidade de árvores, abrindo clareiras para plantas de rápido crescimento.

TABELA 4 - Resultado da análise de variância da variável densidade.

\begin{tabular}{lcc}
\hline Tratamentos & Médias & Resultados do teste \\
\hline Borda & 425,000000 & a1 \\
Centro & 650,000000 & a2 \\
Margem & 712,500000 & a2 \\
\hline
\end{tabular}

Com relação a variável área basal (Tabela 5), mesmo não tendo diferença significativa estatisticamente, pode-se notar um gradiente de aumento da mesma partindo da borda, passando pelo centro, até a margem. Pode ser visto que o efeito de borda, e o efeito do fogo, alteram também a área basal, visto que o tratamento na margem possui um diâmetro maior, fato que altera diretamente a área basal. Para altura, as plantas da borda não apresentaram redução (Tabela 6).

TABELA 5 - Resultado da análise de variância da variável área basal.

\begin{tabular}{lcc}
\hline Tratamentos & Médias & Resultados do teste \\
\hline Borda & 0,187500 & a1 \\
Centro & 0,281250 & a1 \\
Margem & 0,267500 & a1 \\
\hline
\end{tabular}

TABELA 6 - Resultado da análise de variância da variável altura média.

\begin{tabular}{lcc}
\hline Tratamentos & Médias & Resultados do teste \\
\hline Borda & 10,152500 & a1 \\
Centro & 10,877500 & a1 \\
Margem & 9,423750 & a1 \\
\hline
\end{tabular}

Com relação à riqueza de espécies, houve uma diferença altamente significativa entre o tratamento da borda com relação aos tratamentos do centro e margem. O centro e a margem são iguais estatisticamente, e a borda se difere (Tabela 7). Tem-se um gradiente crescente da borda até a margem. No tratamento 
da borda tem-se menor quantidade de espécies, já que poucas espécies invasoras conseguem se estabelecer mais rapidamente e com maior número de indivíduos, impedindo assim o aparecimento de outras espécies. Na margem, tem-se uma maior riqueza, por tratar-se de um local que sofre menos interferência do efeito de borda, e do efeito dos incêndios que ocorreram, já que está localizado mais próximo ao rio que corta o fragmento. Este padrão na riqueza de espécies também foi observado por FREITAS \& MAGALHÃES (2014), que constataram a participação de muitos indivíduos de poucas espécies, representados principalmente por plantas pioneiras, em um fragmento de Mata Atlântica (floresta estacional semidecidual) no estado do Rio de Janeiro.

TABELA 7 - Resultado da análise de variância da variável riqueza de espécies.

\begin{tabular}{lcc}
\hline Tratamentos & Médias & Resultados do teste \\
\hline Borda & 3,500000 & a1 \\
Centro & 5,625000 & a2 \\
Margem & 6,250000 & a2 \\
\hline
\end{tabular}

\section{CONCLUSÕES}

Foram encontradas espécies típicas de Mata Atlântica, como Guarea guidona, da família Meliaceae, entre outras. Fato este que permite classificar o fragmento como tal.

O fragmento apresentou menores valores de diversidade, densidade e biomassa quando comparado com outros estudos em floresta estacional semidecidual, provavelmente por ser envolto em uma matriz urbana.

Há um gradiente de degradação que vai da margem do córrego do Açude até a borda com a matriz urbana, causado pelo fogo e efeito borda.

Por sofrer estes impactos e devido a sua importância regional, devem ser tomadas medidas urgentes de conservação do Jardim Botânico Mata do Açude.

\section{REFERÊNCIAS}

ABDO, M. T. V. N., VALERI,S. V. FERRAUDO. Avaliação do efeito de borda da reserva biológica de Pindorama, SP. Revista Verde, Pombal, v.10., № 4 , p. 01 - 07, out-dez, 2015. Disponível em: <http://www.gvaa.com.br/revista/index.php/RVADS.> Acesso em 09 ago. 2016. DOI: http://dx.doi.org/10.18378/rvads.v10i4.3398.

ANGEL-DE-OLIVEIRA, M. M. Aves que plantam: frugivoria e dispersão de sementes por aves. Boletim CEO, São Paulo, n.13, p.9-12, 1998.

APG. An update of the Angiosperm Phylogeny Group classification for the orders and families of flowering plants: APG III. Botanical Journal of the Linnean Society of London, London, v. 161, p.105-121, 2009. (Impresso)

CAMPANILI, M.; SCHÄFFER, W. B. Mata Atlântica: Patrimônio Nacional dos Brasileiros. Edição 2. Brasília: MMA - Ministério do Meio Ambiente, 2010. 408 p. (Biodiversidade 34).

CARMO, M. R. B.; MORELLATO, L. P. C. Fenologia de árvores e arbustos das matas ciliares da Bacia do Rio Tibagi, estado do Paraná, Brasil. In: RODRIGUES, R. ENCICLOPÉDIA BIOSFERA, Centro Científico Conhecer - Goiânia, v.13 n.24; p.208 2016 
R.; LEITÃO FILHO, H. Matas Ciliares: conservação e recuperação. São Paulo: USP/Fapesp, p. 125-141.2001.

CARVALHO, F. A.; NASCIMENTO, M. T.; BRAGA, J. M. A. Estrutura e composição florística do estrato arbóreo de um remanescente de Mata Atlântica submontana no município de Rio Bonito, RJ, Brasil (Mata Rio Vermelho). Revista Árvore, Viçosa, v. 31, n. 4, p. 717-730, Ago. 2007.4 Disponível em: <http://www.scielo.br/scielo.php?script=sci_arttext\&pid=S010067622007000400017\&lng=en\&nrm=iso>. accesso em 09 Ago. 2016. DOI: http://dx.doi.org/10.1590/S0100-67622007000400017

CARVALHO, P.E.R. Espécies arbóreas brasileiras. Brasília, DF: Embrapa Informação Tecnológica; Colombo: Embrapa Florestas, 2003, v.1. 1039 p. il. (Coleção espécies arbóreas brasileiras, 1).

CIELO FILHO, R.; SANTIN, D. A. Estudo florístico e fitossociológico de um fragmento florestal urbano: Bosque dos Alemães, Campinas, SP. Revista Brasileira de Botânica, São Paulo, v. 25, n. 3, p. 291-301, Set/2002. Disponível em: $<$ http://www.scielo.br/scielo.php?script=sci_arttext\&pid=S010084042002000300005\& Ing=en\&nrm=iso>. Acesso em 23 Ago. 2016. DOl: http://dx.doi.org/10.1590/S010084042002000300005 .

CLIMA: Jataí. 2016. Disponível em: <http://pt.climate-data.org/location/43420/>. Acesso em: 17 jan. 2016.

CONAMA - Conselho Nacional do Meio Ambiente. Resolução no 24, de 31 de janeiro de 1994, define vegetação primária e secundária nos estágios pioneiro, inicial e avançado de regeneração da Mata Atlântica, a fim de orientar os procedimentos de licenciamento de exploração da vegetação nativa do Estado de São Paulo. Diário Oficial da União, Brasília, DF, n. 24, p. 1684-1685, 3 fev. 1994. Seção 1.

FELFILI, J. M.; EISENLOHR, P. V.; MELO, M. M. R. F. Procedimentos e Métodos de Amostragem da Vegetação. In: FELFILI J. M.; EISENLOHR, P. V.; MELO, M. M. R. F.; ANDRADE, L. A.; MEIRA NETO, J. A. A. Fitossociologia no Brasil. Viçosa: Editora UFV, p. 86-121, 2011.

FERREIRA, M. C.; CONSOLARO, H. Fenologia e síndromes de polinização e dispersão de espécies de sub-bosque em um remanescente florestal urbano no Brasil Central. Bioscience Journal, Uberlândia, v. 29, Suplemento 1, p. 1708-1720, Nov/2013. Disponível em: http://www.seer.ufu.br/index.php/biosciencejournal/article/view/ 18072/13372> Acesso em: 09 ago. 2016. ISSN 1981-3163 - Online Journal

FERREIRA, D. F. Sisvar: a Guide for its Bootstrap procedures in multiple comparisons. Ciência agrotecnologia, [online]. 2014, v.38, n.2 [citado 2015-10-17], pp. 109-112. Disponivel em: ISSN 1413-7054. http://dx.doi.org/10.1590/S141370542014000200001. 
FREITAS, W. K.; MAGALHÃES, L. M. S. Florística, diversidade e distribuição espacial das espécies árboreas de um trecho de floresta estacional semidecidual da Serra da Concórdia, RJ. Floresta, Curitiba, PR, v. 44, n. 2, p. 259 - 270, abr. / jun. 2014. (Impresso)

GOOGLE EARTH. Satellite's Image Software: versão 7.1.5.1557 2015. Disponível em <http://earth.google.com>. Acesso em: 16 fev/2016

GUIRÃO, A.C; FILHO, J.T. Preservação de um fragmento florestal urbano - estudo de caso: a ARIE Mata de Santa Genebra, Campinas-SP. GEOUSP - Espaço e Tempo, São Paulo, no 29, p. 147 - 158, 2011. Disponível em: <http://www.revistas.usp.br/geousp/article/view/74193/77836> Acesso em: 09 ago. 2016. DOI: http://dx.doi.org/10.11606/issn.2179-0892.geousp.2011.74193

INSTITUTO BRASILEIRO DE FLORESTAS. (Org.). Bioma Mata Atlântica. Disponível em: <http://www.ibflorestas.org.br/bioma-mata-atlantica.html>. Acesso em: 09 fev. 2016.

MILHOMEM, M. E. V.; ARAÚJO, G. M.; VALE V. S. Estrutura do estrato arbóreo e regenerativo de um fragmento de floresta estacional semidecidual em Itumbiara, GO. Ciência Florestal, Santa Maria, v. 23, n. 4, p. 679-690, out./dez., 2013. Disponível em <http://periodicos.ufsm.br/cienciaflorestal/article/view/12352/7812> Acesso em: 09 ago. 2016. DOI: http://dx.doi.org/10.5902/1980509812352.

MOREIRA, B.; CARVALHO, F. A. A comunidade arbórea de um fragmento urbano de Floresta Atlântica após 40 anos de sucessão secundária (Juiz de Fora, Minas Gerais). Biotemas, Florianópolis, v. 26 n.2, p. 59-70, jun/2013. Disponível em: < https://periodicos.ufsc.br/index.php/biotemas/article/view/21757925.2013v26n2p59/2 4694> DOI: http://dx.doi.org/10.5007/2175-7925.2013v26n2p59.

PRADO JÚNIOR, J.A.; LOPES, S.F.; SCHIAVINI, I.; VALE, V.S.; OLIVEIRA, A.P. GUSSON, A.E.; DIAS NETO, O.C.; STEIN, M. Fitossociologia, caracterização sucessional e síndromes de dispersão da comunidade arbórea de remanescente urbano de Floresta Estacional Semidecidual em Monte Carmelo, Minas Gerais. Rodriguésia, Rio de Janeiro, v. 63, n. 3, p. 489-499, Set/2012. Disponível em: <http://www.scielo.br/scielo.php?script=sci_arttext\&pid=S217578602012000300001\& Ing=en\&nrm=iso $>$. Acesso em 23 Ago. 2016. DOl: http://dx.doi.org/10.1590/S217578602012000300001.

PRADO JÚNIOR, J. A.; LOPES, S.; VALE, V.; OLIVEIRA, A.P.; GUSSON, A. E.; DIAS-NETO, O.; SCHIAVINI, I. Estrutura e caracterização sucessional da comunidade arbórea de um remanescente de floresta estacional semidecidual, Uberlândia, MG. Caminhos de Geografia, Uberlândia, MG, v. 12, n. 39, p.81-93, set/2011. Disponível em: <http://www.ig.ufu.br/revista/caminhos.html> Acesso em: 09 ago. 2016. ISSN 1678-6343

SÁ, D.; LOPES, S.; PRADO JÚNIOR, J A.; SCHIAVINI, I.; VALE, V.; OLIVEIRA, ENCICLOPÉDIA BIOSFERA, Centro Científico Conhecer - Goiânia, v.13 n.24; p.210 2016 
A.P.; DIAS-NETO, O.; GUSSON, A. E. Estrutura e grupos ecológicos de um fragmento de floresta estacional semidecidual no Triangulo Mineiro, Brasil. Caminhos de Geografia, Uberlândia, MG, v. 13, n. 44, p.89-101, dez/2012. Disponível em: <http://www.seer.ufu.br/index.php/caminhosdegeografia> Acesso em: 09 ago. 2016. ISSN 1678-6343

SWAINE, M. D.; WHITMORE, T. C. On the definition of ecological species groups in tropical rain forest. Vegetatio, v. 75, n. 2, p81-86, 1988. Impresso.

TANUS, M.R.; PASTORE, M.; BIANCHINI, R.S.; GOMES, E.P.C. Estrutura e composição de um trecho de Mata Atlântica no Parque Estadual das Fontes do Ipiranga, São Paulo, SP, Brasil. Hoehnea, São Paulo, v. 39, n. 1, p. 157-168, Mar/ 2012. Disponível em: <http://www.scielo.br/scielo.php?script=sci_arttext\&pid=S223689062012000100010\&lng=en\&nrm=iso>. Acesso em: 23 Ago. 2016. DOI: http://dx.doi.org/10.1590/S2236-89062012000100010.

TROIAN, L. C.; KÄFFER, M. I.; MÜLLER, S. C.; TROIAN, V. R.; GUERRA, J.; BORGES, M. G.; GUERRA, T.; RODRIGUES, G. G.; FORNECK, E. D. Florística e padrões estruturais de um fragmento floresta urbano, região metropolitana de Porto Alegre, RS, Brasil. IHERINGIA, Série Botânica, v. 66, n. 1, p. 5-16, 2011. Disponível em: $\quad$ <http://www.fzb.rs.gov.br/upload/20140328103917ih66_1_p005_016.pdf> Acesso em 23 Ago. 2016.

VENTUROLI, F.; FELFILI, J. M.; FAGG, C. W. Avaliação temporal da regeneração natural em uma floresta estacional semidecídua secundária, em Pirenópolis, Goiás. Revista Árvore, Viçosa, v. 35, n. 3, p. 473-483, Jun/2011. Disponível em <http://www.scielo.br/scielo.php?script=sci_arttext\&pid=S010067622011000300010\& Ing=en\&nrm=iso>. Acesso em 09 Ago. 2016. DOI: http://dx.doi.org/10.1590/S010067622011000300010 .

VENZKE, T.S.; MARTINS, S.V.; NERI, A.V.; KUNZ, S.H. Síndromes de dispersão de sementes em estágios sucessionais de mata ciliar, no extremo sul da Mata Atlântica, Arroio do Padre, RS, Brasil. Revista Árvore, Viçosa, v. 38, n. 3, p. 403-413, jun/ 2014. Disponível em: <http://www.scielo.br/scielo.php?script=sci_arttext\&pid= S010067622014000300002\&lng=en\&nrm=iso>. Acesso em 23 Ago. 2016. DOI: http://dx.doi.org/10.1590/S0100-67622014000300002.

VIDA, Instituto. Estudo Técnico para Criação de Unidade de Conservação na Categoria "Parque Municipal Mata do Açude" no Município de Jataí/GP. Jataí GO. 2015. 78 p. 